\title{
ODONTOMA RELATO DE CASO CLÍNICO
}

Rômulo MOLINARI, Leonardo Silva BENATO, João Luiz CARLINI

Os odontomas merecem atenção do clinico geral por ser considerado o tumor odontogênico mais comum. $\mathrm{O}$ objetivo deste trabalho é apresentar um caso clínico de odontoma composto associado à dor de ouvido. Paciente mulher, 47 anos, melanoderma, apresentava quadro sistêmico de depressão e fibromialgia controlados a um e quatro anos respectivamente, e estava sob tratamento por dor de ouvido há dois anos no Hospital de Clínicas. A paciente procurou um cirurgião dentista por conta própria, e este requisitou uma radiografia panorâmica, onde foi constatada imagem radiopaca multilocular na região do forame mentual do lado direito. Foi realizado o tratamento cirúrgico com enucleação e curetagem, em ambulatório com anestesia loco-regional. A incisão estendeu-se do dente 46 seguindo o rebordo e continuando intrasulcular até o dente 41. O acesso ósseo foi realizado em formato circular, removendo a cortical vestibular e retirando a lesão por inteiro. Todos os fragmentos foram enviados para exame anatomopatológico obtendo-se 0 diagnóstico histopatológico de odontoma composto. Após seis meses de proservação o local da cirurgia mostra neoformação óssea e paciente relatou melhora das dores, o que leva a acreditar que a lesão comprimia o nervo mentual.

Palavras-chave: Odontoma; Mandíbula. 